\section{Trichoblastic Carcinoma Arising from a Nevus Sebaceous}

Jin-Tae Kim ${ }^{1}$, Soo-Hyang Lee ${ }^{1}$, Pil-Dong Cho ${ }^{1}$, Hyun-Woo Shin ${ }^{1}$, Han-Seong Kim ${ }^{2}$

Departments of ${ }^{1}$ Plastic and Reconstructive Surgery and ${ }^{2}$ Pathology, Ilsan Paik Hospital, Inje University College of Medicine, Goyang, Korea

Correspondence: Soo-Hyang Lee

Department of Plastic and Reconstructive Surgery, Ilsan Paik Hospital, Inje University College of Medicine, 170 Juhwa-ro, Ilsanseo-gu, Goyang 10380, Kore

Tel: +82-31-910-7320, Fax: +82-31-910-7814, E-mail: shaynglee@naver.com

No potential conflict of interest relevant to this article was reported.

Received: 20 Oct $2015 \bullet$ Revised: 29 Dec $2015 \bullet$ Accepted: 18 Jan 2016 pISSN: 2234-6163 • elSSN: 2234-6171

http://dx.doi.org/10.5999/aps.2016.43.3.297

Arch Plast Surg 2016;43:297-299

Copyright (C) 2016 The Korean Society of Plastic and Reconstructive Surgeons This is an Open Access article distributed under the terms of the Creative Commons Attribution Non-Commercial License (http://creativecommons.org/licenses/by-nc/4.0) Attribution Non-Commercial License (http://creativecommons.org/licenses/by-nc/4.0/
which permits unrestricted non-commercial use, distribution, and reproduction in any which permits unrestricted non-commercial use, dist
medium, provided the original work is properly cited.

Nevus sebaceous is a hamartoma of the cutaneous structures that often presents at birth and typically involves the face and scalp. Nevus sebaceous is frequently complicated by the development of a variety of other benign or malignant neoplasms. The most frequently reported benign neoplasms are trichoblastoma and syringocystadenoma papilliferum. Malignant tumors are much less frequently observed in association with nevus sebaceous and include basal cell carcinoma, squamous cell carcinoma, sebaceous carcinoma, and others [1]. However, no previous reports have described trichoblastic carcinoma occurring secondarily to nevus sebaceous. We report a case of malignant trichoblastoma that arose from nevus sebaceous of the scalp in a 38-year-old woman.

A 38-year-old woman visited our clinic with a mass arising from a birthmark on the left parietal scalp. Six months prior to the visit, an erythematous mass had enlarged gradually in the plaque. Her chief complaints associated with the mass were itching, pain, and bleeding easily after small traumas. Physical examination of the scalp revealed a $5 \times 2-\mathrm{cm}$ yellowish, verrucous, hairless plaque, and a distinct $1.5 \times 1.5$-cm erythematous nodule was contained within it (Fig. 1). She had no personal or family history of underlying skin diseases or malignancies. A punch biopsy was done from the erythematous nodule, and showed that the mass was a malignant skin adnexal tumor. Therefore, she underwent complete surgical excision with $0.5 \mathrm{~mm}$ of normal skin surrounding the margins of the nevus sebaceous (Fig. 2). A frozen section biopsy showed that no tumor cells were present in the resection margin. The skin defect was then covered with a transpositional flap and primary closure was performed (Fig. 3). A histopathologic examination of the mass was performed, revealing the presence of a nodular tumor, which was diagnosed as trichoblastic carcinoma. It was composed of basaloid epithelial nests and strands. Some nodules showed central necrosis (Fig. 4). Nuclear atypia was present, as well as increased mitotic activity in a high-power view (Fig. 5).

After confirming its malignancy, the patient was carefully evaluated for evidence of metastasis. A full body positron emission tomography-computed tomography (PET-CT) scan revealed no regional or distant metastasis. The patient is now under followup care.

Malignant trichoblastoma is a rare malignant adnexal tumor originating from the hair germ cells. Malignant changes in trichoblastoma may be related to its epithelial component (trichoblastic carcinoma), stromal component (trichoblastic sarcoma), or both (trichoblastic carcinosarcoma). Trichoblastic carcinoma usually presents on the scalp and face in

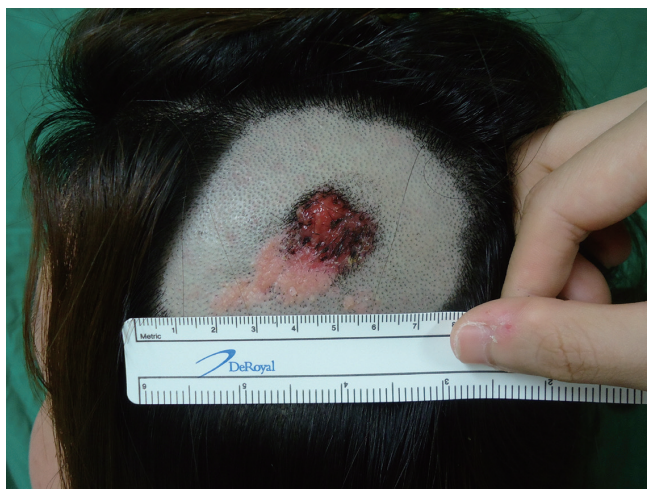

Fig. 1.

Preoperative appearance. A papillary erythematous mass arose within a yellowish verrucous nevus sebaceous on the left parietal scalp.

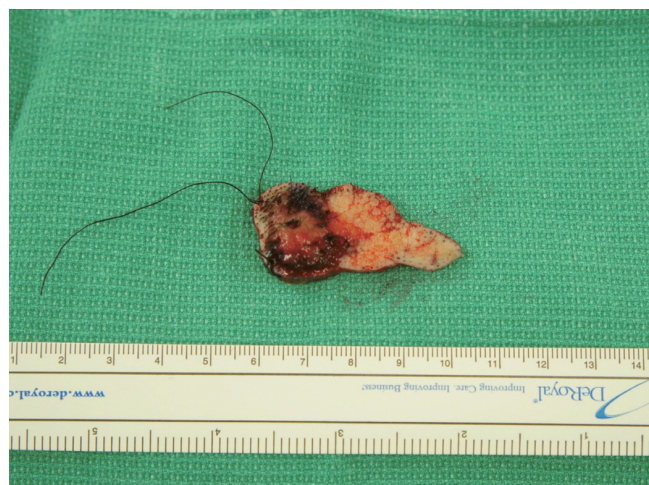

Fig. 2.

A $4.7 \times 1.8 \times 0.4-\mathrm{cm}$ oval, elevated lesion is seen, with an area of focal black pigmentation measuring $1.4 \times 1.5 \mathrm{~cm}$. 
Fig. 3.

Postoperative view. The defect was reconstructed using a transpositional flap and primary closure.

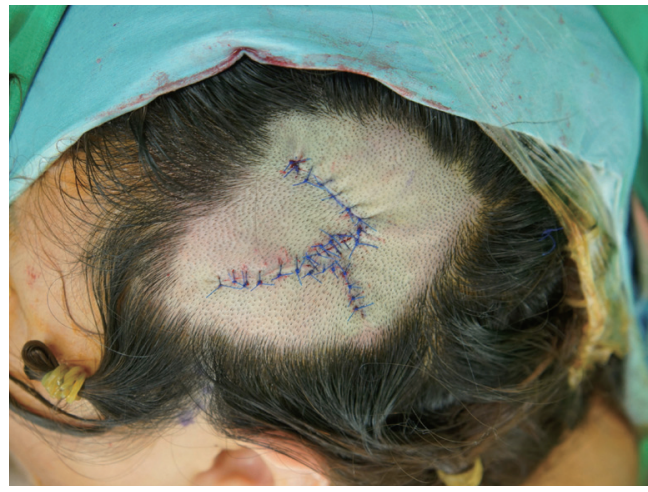

Fig. 4.

A low-power view reveals a vaguely nodular tumor. The tumor nodules were composed of variably sized nests of basaloid cells. Some tumor nodules had central necrosis (white arrow). Deep erosion was noted with loss of the epidermis $\left(H \& E_{1} \times 40\right)$.

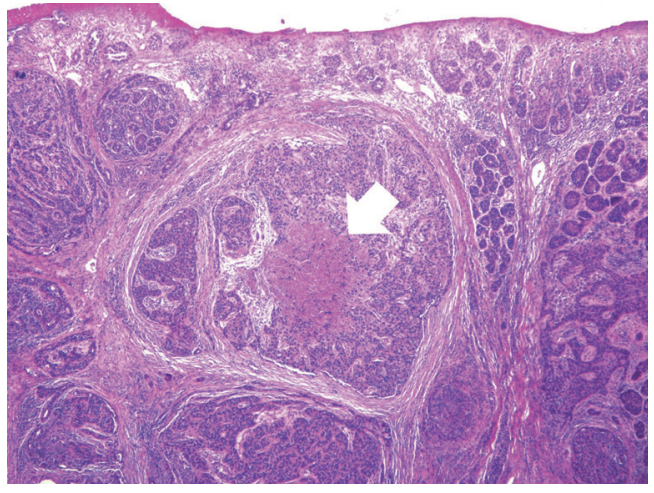

middle-aged to elderly adults, who are often younger than patients with basal cell carcinoma. This patient was relatively young, at 38 years of age. According to the level of clinical malignancy, these tumors are divided into low-grade and high-grade lesions. Low grade trichoblastic carcinomas are characterized by the morphological aspects of trichoblastoma, but show infiltrative growth with the involvement of deeper tissues. They have also been referred to as aggressive trichoblastoma. They appear to grow slowly, with nodules or plaques occurring on the face that do not recur if completely removed. High-grade trichoblastic carcinomas have only been described recently, and are characterized by rapid enlargement with inflammation, a large size $(>3 \mathrm{~cm})$, necrosis, and a predilection for the trunk and extremities. They have the potential to exhibit aggressive clinical behavior and systemic spread, particularly to the lung $[2,3]$. A total of 13 cases of trichoblastic carcinoma have been reported in the literature, comprising seven low-grade and six high-grade carcinomas. Two patients with high-grade trichoblastic carcinomas are known to have died due to systemic progression of the disease [2].

All authors agree that surgery with complete removal is the treatment of choice. However, due to rarity of the disease, the optimal surgical margins

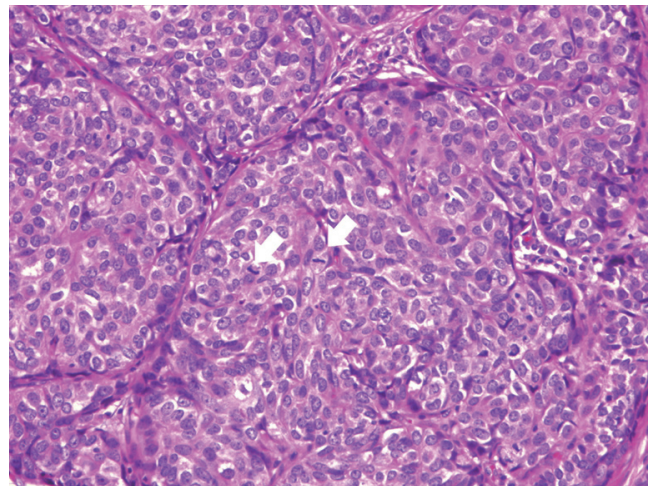

Fig. 5.

A high-power view shows atypical round to oval tumor cells. Many mitotic figures are visible (white arrows). Nuclear pleomorphism is present, with small nucleoli $\left(H \& E_{1} \times 200\right)$.

have not yet been established. Ayhan et al. [3] reported a case of trichoblastic carcinoma in a 73-year-old woman. The tumor was excised with 0.5 $\mathrm{mm}$ of normal skin surrounding the margins, and the lesion was found to be a tumor with a free margin Cowen et al. [4] described a case of locally invasive trichoblastoma in which the tumor was excised in four stages using Mohs micrographic surgery. However, in this case, we performed wide excision with a safety margin of $0.5 \mathrm{~mm}$ surrounding the nevus sebaceous. The frozen section biopsy showed no tumor cells on the resection margin. Furthermore, PET-CT did not show metastasis. Over the course of 12 months of follow-up, our patient did not present with any signs of local or distant recurrence. We plan to observe her for the next five years. When surgical treatment is not possible due to unresectability of the cancer or because patients cannot undergo a reoperation after the first excision, radiotherapy may be considered as an adjuvant treatment [5].

We experienced a very rare case of trichoblastic carcinoma. Only 13 cases of malignant trichoblastic tumors have been reported in the literature. This is the only case of trichoblastic carcinoma that has been reported to occur in a nevus sebaceous. We obtained satisfactory treatment results using wide excision with a safety margin of $0.5 \mathrm{~mm}$ surrounding the nevus sebaceous, as verified by a frozen section biopsy. Herein, we report our case with a literature review.

\section{References}

1. Cribier B, Scrivener Y, Grosshans E. Tumors arising 
in nevus sebaceus: a study of 596 cases. J Am Acad Dermatol 2000;42:263-8.

2. Laffay L, Depaepe L, d'Hombres A, et al. Histological features and treatment approach of trichoblastic carcinomas: from a case report to a review of the literature. Tumori 2012;98:46e-49e.

3. Ayhan M, Gorgu M, Aytug Z, et al. Trichoblastic carcinoma of the alar region: a case report. Dermatol Surg 2006;32:976-9.

4. Cowen EW, Helm KF, Billingsley EM. An unusually aggressive trichoblastoma. J Am Acad Dermatol 2000;42:374-7.

5. Harari PM, Shimm DS, Bangert JL, et al. The role of radiotherapy in the treatment of malignant sweat gland neoplasms. Cancer 1990;65:1737-40.

\section{Bilateral Atypical Ductal Hyperplasia with Microcalcifications in a Patient with Gynecomastia}

Pedro Vidal ${ }^{1}$, Juan Enrique Berner ${ }^{1}$, Alejandra Klenner ${ }^{1}$, Óscar Tapia ${ }^{2,3}$

${ }^{1}$ Clínica La Parva, Instituto Clínico White, Santiago; ${ }^{2}$ Citolab Laboratory, Santiago; ${ }^{3}$ Universidad de La Frontera, Temuco, Chile

Correspondence: Pedro Vidal

Clinica La Parva, Instituto Clínico White, Av. Las Condes 13.305, Santiago, Chile Tel: +56-2-2207-1125, E-mail: pvidalg@mac.com

This study was presented at the 12th Chilean Congress of Breast Surgery on September 27th-29th, 2015, in Pucon, Chile.

No potential conflict of interest relevant to this article was reported.

Received: 1 Dec 2015 • Revised: 20 Jan 2016• Accepted: 7 Feb 2016 pISSN: 2234-6163 • elSSN: 2234-6171

http://dx.doi.org/10.5999/aps.2016.43.3.299

Arch Plast Surg 2016;43:299-301

Copyright (C) 2016 The Korean Society of Plastic and Reconstructive Surgeon This is an Open Access article distributed under the terms of the Creative Commons Attribution Non-Commercial License (http://creativecommons.org/licenses/by-nc/4.0/) which permits unrestricted non-commercial use, distribution, and reproduction in any medium, provided the original work is properly cited.

The incidence of male breast cancer is far lower than that of breast cancer in female patients, and usually has a worse prognosis. The incidental discovery of breast cancer in patients undergoing surgery for gynecomastia is rare, but has previously been reported by several authors [1]. However, bilateral atypical ductal hyperplasia in men is far less frequent, and this is the first report to describe the occurrence of this finding with associated microcalcifications in the histopathological analysis.

We present the case of a 39-year-old male patient who attended a plastic surgery consultation complaining of long standing bilateral gynecomastia (Fig. 1). He had no personal history of any significant medical conditions or family history of breast cancer. He also denied the use of medication and recreational drugs. Physical examination revealed bilateral breast enlargement with palpable glandular tissue below and surrounding the nipple-areolar complex, with adjacent fat tissue. A testicular examination was normal.

Routine preoperative laboratory tests did not show any alterations in transaminase, plasma creatinine, or thyroid hormone levels. The presence of bilateral glandular breast tissue was confirmed using ultrasound imaging.

A combined technique was used to correct this patient's gynecomastia by performing tumescent liposuction of the thorax followed by transareolar resection of the breast tissue. The operation was uneventful, with $45 \mathrm{~g}$ of glandular tissue on the left side and $23 \mathrm{~g}$ on the right side. The surgical outcome and the patient's postoperative course were satisfactory, and he was discharged the following day without further complications (Fig. 2).

The histopathological analysis reported several samples in which stromal fibrosis with hyaline parts was found. Irregular ductal structures were identified, inlaid with hyperplastic epithelium following a

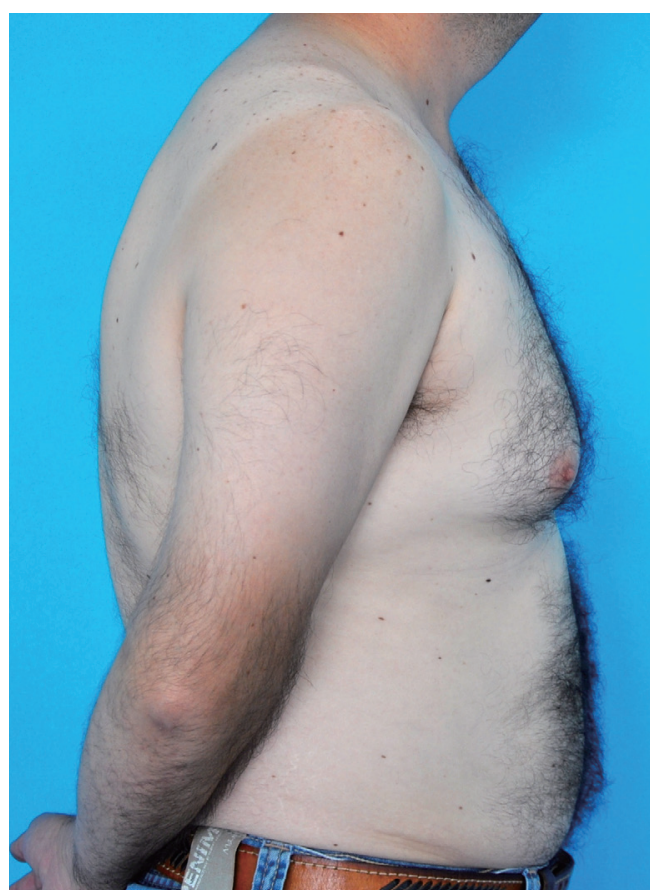

Fig. 1.

Preoperative photograph with evident breast enlargement. 